\title{
La aplicación de la doctrina del Tribunal de Justicia de la Unión Europea sobre el concepto de discapacidad. Comentario a las sentencias del Tribunal Supremo de 22 de mayo de 2020 (rec. 2684/2017) y de 15 de septiembre de 2020 (rec. 3387/2017)*
}

\author{
The application of the Court of Justice of the European Union's interpretation about the \\ concept of disability. Commentary on the Supreme Court's rulings of 22 May 2020 (rec. \\ 2684/2017) and 15 September 2020 (rec. 3387/2017) \\ SILVIA FERNÁNDEZ MARTÍNEZ** \\ Investigadora Postdoctoral del Área de Derecho del Trabajo y de la Seguridad Social \\ Universidad de Alcalá (España) \\ silvia.fernandezm@uah.es
}

https://orcid.org/0000-0002-9093-4100

\begin{abstract}
Resumen: El artículo analiza dos sentencias recientes del TS en las que ha aplicado la interpretación del TJUE sobre el concepto de discapacidad de la Directiva 2000/78/CE. Ambas sentencias resuelven recursos para la unificación de doctrina sobre supuestos de hecho similares y en los que se utiliza la sentencia del TJUE sobre el caso Daouidi como sentencia de contraste. En ambas resoluciones, el TS concluyó que, en los casos concretos que examinó, no se daban los elementos necesarios para considerar que los trabajadores despedidos después o durante una situación de IT cumpliesen con los requisitos exigidos por el TJUE, para entender que eran personas con discapacidad. En consecuencia, concluyó
\end{abstract}

Cómo citar este trabajo: FERNÁNDEZ MARTÍNEZ, Silvia, "La aplicación de la doctrina del Tribunal de Justicia de la Unión Europea sobre el concepto de discapacidad. Comentario a las sentencias del Tribunal Supremo de 22 de mayo de 2020 (rec. 2684/2017) y de 15 de septiembre de 2020 (rec. 3387/2017)", Revista de Estudios Jurídicos y Criminológicos, ISSN-e: 2660-7964, n. ${ }^{\circ}$ 2, Universidad de Cádiz, 2020, pp. 233-241, DOI: https://doi.org/10.25267/REJUCRIM.2020.i2.09

* Este trabajo se ha realizado en el marco del Proyecto de investigación "La salud del trabajador ante los retos laborales del futuro" (CM/JIN/2019-029). IP: Silvia Fernández Martínez. Entidades financiadoras: Comunidad de Madrid, Universidad de Alcalá. Programa de apoyo a la realización de Proyectos de I+D para jóvenes investigadores de la Universidad de Alcalá. Acción financiada por la Comunidad de Madrid en el marco del Convenio Plurianual con la Universidad de Alcalá en la línea de actuación "Programa de Estímulo a la Investigación de Jóvenes Investigadores”.

** Programa de Atracción del Talento Investigador a Grupos de investigación de la Comunidad de Madrid. 
que las sentencias recurridas habían aplicado correctamente la doctrina del TJUE y que, por lo tanto, los despidos de esos trabajadores debían de calificarse como improcedentes y no como nulos.

Abstract: The papers analyzes two recent decisions in which the Supreme Court has applied the interpretation of the CJEU about the concept of disability of the Directive 2000/78/EC. Both rulings resolve appeals for the unification of doctrine on similar factual assumptions. The ruling of the CJEU on the Daouidi case is used as a contrasting judgment. In both resolutions, the Supreme Court concluded that, in the specific cases examined, there were no elements to consider that the workers dismissed after or during an incapacity period met the requirements demanded by the CJEU, to understand that they were people with disability. Consequently, it concluded that the appealed rulings had correctly applied the doctrine of the CJEU and that, therefore, the dismissals of these workers should be classified as unfair and not as invalid.

Palabras claves: discapacidad, Directiva 2000/78/CE, TJUE, Daouidi, incapacidad temporal, despido.

Keywords: disability, Council Directive 2000/78/CE, CJEU, Daouidi, temporarily unable to work, dismissal.

Sumario: 1. INTRODUCCIÓN. 2. SUPUESTOS DE HECHO. 3. LA DOCTRINA DAOUIDI Y SU APLICACIÓN POR PARTE DEL TRIBUNAL SUPREMO. 4. VALORACIÓN CRÍTICA.

\section{INTRODUCCIÓN}

Las sentencias del Tribunal Supremo (en adelante, TS) de 22 de mayo ${ }^{1}$ y de 15 de septiembre de $2020^{2}$ resolvieron sendos recursos para la unificación de doctrina, cuyo objeto consistía en determinar si el despido de un trabajador que había estado en situación de incapacidad temporal (en adelante, IT) en los meses anteriores y el de otro que se encontraba de baja médica en el momento de la extinción de la relación contractual debían de calificarse como nulos o improcedentes. En ambas sentencias, el TS ha analizado si los tribunales españoles han aplicado de forma correcta la interpretación que el Tribunal de Justicia de la Unión Europea (en adelante, TJUE) realizó del concepto de discapacidad recogido en la Directiva 2000/78/CE del Consejo, de 27 de noviembre de 2000, relativa al establecimiento de un marco general para la igualdad de trato en el empleo y la ocupación en su sentencia de 1 de diciembre de 2016, asunto Daouidi ${ }^{3}$.

\footnotetext{
${ }^{1}$ N. recurso 2684/2017. Para un breve comentario de esta sentencia, véase el post en el blog del profesor Ignasi Beltrán: "Bajas por incapacidad temporal, despido injustificado y ulterior incapacidad permanente total pueden no ser suficientes para apreciar discriminación 'ex' Daouidi (STS 22/5/20)". Disponible en: https://ignasibeltran.com/2020/06/23/bajas-por-incapacidad-temporal-despido-injustificado-y-ulteriorincapacidad-permanente-total-pueden-no-ser-suficientes-para-apreciar-discriminacion-ex-daouidi-sts-22-5-20/

${ }^{2}$ N. recurso. 3387/2017.

${ }^{3} \mathrm{C}-395 / 17$.
} 
Dadas sus similitudes, ya que resuelven casos similares, y la sentencia de 15 de septiembre de 2020 reproduce, en parte, los fundamentos de derecho de la dictada el 22 de mayo del mismo año, en el presente comentario las examinaremos de forma conjunta.

Antes de las sentencias que ahora se analizan, el TS ya había tenido ocasión de pronunciarse sobre la aplicación de la doctrina Daouidi en otras ocasiones. En concreto, en la sentencia de 22 de febrero de $2018^{4}$, en la de 15 de marzo de $2018^{5}$, y también en la de 20 de marzo de $2019^{6}$. En todas ellas hizo referencia a la interpretación amplia del concepto de discapacidad realizada por el TJUE. Sin embargo, aunque afirmó estar siguiendo dicha doctrina, en ninguna de ellos entendió que, efectivamente, existiese discapacidad. En sus últimas sentencias sobre el particular del año 2020, el TS, aplicando la doctrina Daouidi, llegó a la misma conclusión, es decir, entendió de que la situación de los demandantes no era constitutiva de discapacidad, pues no se cumplían los requisitos exigidos por el TJUE en la sentencia sobre el caso Daouidi.

\section{SUPUESTOS DE HECHO}

La sentencia del TS de 22 de mayo de 2020 resolvió un recurso para la unificación de doctrina interpuesto contra la sentencia del Tribunal Superior de Justicia (en adelante, TSJ) del País Vasco, de 9 de mayo de 2017 ${ }^{7}$. El TSJ confirmó la sentencia del Juzgado de lo Social $\mathrm{n}^{\mathrm{o}} 2$ de Donostia de 12 de enero de $2017^{8}$, que había calificado el despido del actor por parte de la empresa demandada como improcedente. Sin embargo, el recurso presentado ante el TS perseguía la declaración de nulidad de dicho despido, por infracción de los arts. 17.1, 53.4 y 55.3.4 y 5 del Estatuto de los trabajadores (en adelante, ET), del Convenio n. 158 de la Organización Internacional del Trabajo (OIT) sobre la terminación de la relación de trabajo de 1982, y también de la Directiva 2000/78/CE. El actor entendía que el despido era nulo porque traía su causa en el hecho de que el trabajador había estado en situación de IT, en diversas ocasiones, en los meses anteriores al despido. Pese a que el recurrente consideraba que eran varios los preceptos vulnerados, la sentencia objeto de análisis se centró en los aspectos relacionados con la Directiva 2000/78/CE.

Por su parte, en la sentencia de 15 de septiembre de 2020, el TS se pronunció sobre un recurso para la unificación de doctrina interpuesto contra la sentencia del TSJ de Castilla-León (Burgos) de 20 de julio de $2017^{9}$. En dicha sentencia, el TSJ resolvió el recurso de suplicación interpuesto

\footnotetext{
${ }^{4}$ N. recurso $160 / 2016$.

${ }^{5}$ N. recurso 2766/2016. Para un comentario de esta sentencia, véase: GUTIÉRREZ COLOMINAS, D., "La discriminación por discapacidad en las extinciones por ineptitud sobrevenida. Comentario a la STS de 22 de febrero de 2018 (Rec 160/2016)", Derecho de las relaciones laborales, n. 5, 2018.

${ }^{6}$ N. $1784 / 2017$.

${ }^{7}$ N. recurso de suplicación 906/2017.

${ }^{8}$ Autos n. 585/2016

${ }^{9}$ N. recurso 484/2017.
} 
por ambas partes frente a la sentencia del Juzgado de lo Social $\mathrm{n}^{\circ} 1$ de Burgos de 28 de febrero de $2017^{10}$. La sentencia de instancia había estimado la demanda interpuesta por el trabajador contra la empresa y había declarado nulo su despido. Sin embargo, el TSJ de Castilla-León estimó el recurso interpuesto por la representación de la empresa, por lo que revocó la resolución del Juzgado de lo Social y calificó el despido como improcedente. El recurso para la unificación de doctrina que se presentó ante el TS perseguía la revocación de la sentencia del TSJ y la confirmación de la de instancia.

En los escritos de interposición del recurso de casación para la unificación de doctrina resueltos por ambas sentencias, los recurrentes seleccionaron como sentencia de contraste la dictada por el TJUE de 1 de diciembre de 2016, asunto Daouidi, opción que el TS admitió en ambos supuestos. Esta posibilidad aparece recogida en el art. 219.2 de la Ley 36/2011, de 10 de octubre, reguladora de la jurisdicción social (en adelante, LRJS) que establece que, si se cumplen los requisitos mencionados en el art. 219.1 LRJS “podrá alegarse como doctrina de contradicción la establecida en las sentencias dictadas por el Tribunal Constitucional y los órganos jurisdiccionales instituidos en los Tratados y Acuerdos internacionales en materia de derechos humanos y libertades fundamentales ratificados por España, siempre que se cumplan los presupuestos del número anterior referidos a la pretensión de tutela de tales derechos y libertades". En todo caso, en la sentencia de 20 de mayo de 2020, razonamiento que reproduce en la de 15 de septiembre, el TS indica que "el análisis de las identidades deberá efectuarse igualmente con arreglo al apartado 1 del mismo art. 219 LRJS, pues el hecho de que el legislador haya relajado la contradicción no significa que la misma haya desaparecido". En consecuencia, tal y como había establecido el TS en sentencias anteriores, "no se exige la identidad integral habitual ("hechos, fundamentos y pretensiones") pero sí la homogeneidad en los debates (problema suscitado)" "11. Si bien lo más habitual es que las sentencias de contraste que se utilizan en los recursos para la unificación de doctrina pertenezcan a los TSJ, nada impide que se opte por emplear una del TJUE. Con todo, llama la atención que, en estos supuestos concretos, los recurrentes no hayan propuesto como sentencias de contraste las dictadas por otro TSJ, pese a que son varias las que, en supuestos de hecho similares, han considerado que sí existía discapacidad y, por lo tanto, calificaron el despido como nulo ${ }^{12}$.

En ambas sentencias, el TS concluyó que el análisis específico del supuesto concreto obliga al estudio de la sentencia del TJUE sobre el caso Daouidi, cuya doctrina se invoca para la contradicción. Además, el TS afirmó que hay es necesario tener en cuenta que, si la respuesta es positiva, es decir, si se llega a la conclusión de que la sentencia del TSJ del País Vasco contradice la del TJUE, habría que determinar si decisión recurrida se aparta de una aplicación

\footnotetext{
${ }^{10}$ Autos n. 46/17.

${ }^{11}$ STS de 14 noviembre 2014 (n. recurso 1839/2013).

12 Véanse, a modo de ejemplo, STSJ País Vasco de 19 diciembre 2017 (n. recurso 2345/2017) y STSJ País Vasco de 26 septiembre 2017 (n. recurso 1734/2017).
} 
del Derecho respetuosa con el Derecho de la Unión. En consecuencia, el TS dedicó el resto de las páginas que conforman ambas sentencias a analizar la sentencia Daouidi.

En la sentencia de 22 de mayo de 2020 constan probados los hechos que se explican a continuación. El trabajador despedido, conductor mecánico en ruta, prestaba servicios para la empresa demandada desde el 18 de junio de 2003. Fue despedido con efectos de 14 de septiembre de 2016 "por diferencias insostenibles con la empresa". Sin embargo, la empresa reconoció la improcedencia del despido. El actor estuvo en situación de IT en los siguientes periodos: del 6 al 12 de junio de 2016; del 17 de junio al 8 de septiembre de 2016; desde el 26 de septiembre de 2016 hasta, cuando menos, la fecha de celebración de la vista. En la sentencia dictada por el Juzgado de lo Social $n^{\circ} 2$ de Donostia figuraba, como hecho probado, que el actor había sufrido un accidente de trabajo el 20 de abril de 2016. Sin embargo, en el recurso de suplicación ante el TSJ del País Vasco, el recurrente solicitó su revisión, pues afirmaba que se trataba de un error de transcripción, ya que el accidente se había producido en el año 2005, y no en 2016. Con todo, el TSJ desestimó dicha pretensión al entender que existían contracciones, puesto que, de otros documentos presentes en las actuaciones, se deducía que el accidente de trabajo había tenido lugar el 20 de abril de 2015. En consecuencia, el TS llegó a la conclusión de que el accidente no estaba conectado con la IT del trabajador en los periodos del 6 al 12 de junio de 2016 y del 17 de junio a 8 septiembre de 2016. Además, el TS también recordó que el recurrente fue declarado en situación de incapacidad permanente (IP) total por resolución del Instituto Nacional de la Seguridad Social (en adelante, INSS) de 15 de julio de 2017.

Por otro lado, en el caso resuelto por la sentencia de 15 de septiembre de 2020, el trabajador prestaba servicios como peón y se dedicaba al lavado de maquinaria industrial, desde el 5 de junio de 2015. Fue despedido de forma verbal el 2 de diciembre de 2016, mientras se encontraba en un periodo de baja médica, que había iniciado el 26 de noviembre de 2016.

\section{LA DOCTRINA DAOUDI Y SU APLICACIÓN POR PARTE DEL TRIBUNAL SUPREMO}

La sentencia dictada por el TJUE en el caso Daouidi resolvió una cuestión prejudicial presentada por el Juzgado $n^{\circ} 33$ de Barcelona, en la que se planteaba al TJUE si la limitación de la capacidad que da lugar a un proceso de IT de duración incierta puede calificarse como duradera y, por lo tanto, interpretarse que está incluida en el concepto de discapacidad al que hace referencia la Directiva 2000/78/CE ${ }^{13}$. El TJUE concluyó que "el hecho de que el interesado

\footnotetext{
${ }^{13}$ Esta sentencia ha sido objeto de numerosos análisis por parte de la doctrina laboralista. Véase, entre otros, FERNÁNDEZ MARTÍNEZ, S., "Incapacidad temporal y discriminación por discapacidad: reflexiones al hilo del caso Daouidi", Trabajo y Derecho: nueva revista de actualidad y relaciones laborales, n. 28, 2017; DESDENTADO DAROCA, E., "El despido del enfermo y la STJUE de 1 de diciembre de 2016 dictada en el caso Daouidi. Algunas reflexiones críticas", Revista de información Laboral, n. 3, 2017; AGUSTÍ MARAGALL, J., "El "Caso Daouidi”: iter procesal, preguntas y respuestas. La objetivación de la "limitación duradera" como situación de discapacidad", Trabajo y Derecho: nueva revista de actualidad y relaciones laborales, $\mathrm{n}$. Monográfico 6, 2017; y SÁNCHEZ PÉREZ, J., "Es discriminatorio despedir en situación de incapacidad laboral? Los nuevos límites comunitarios. Comentario a la Sentencia del Tribunal de Justicia de la Unión Europea de 1 de
} 
se halle en situación de incapacidad temporal, con arreglo al Derecho nacional, de duración incierta, a causa de un accidente laboral no significa, por sí solo, que la limitación de su capacidad pueda ser calificada de "duradera", con arreglo a la definición de "discapacidad" mencionada por esa Directiva, interpretada a la luz de la Convención de la ONU sobre personas con discapacidad". A continuación, el TJUE se centró en analizar los indicios que permitirían considerar que tal limitación era duradera. Entre ellos, destaca el hecho de que la incapacidad del interesado que dio lugar al hecho presuntamente discriminatorio no presentase una perspectiva bien delimitada en cuanto a su finalización a corto plazo en el momento en que dicho acto se produjo, o también cuando no pudiese saberse si dicha incapacidad iba a prolongarse significativamente antes del restablecimiento de dicha persona. Por último, el TJUE apuntó que, para comprobar el carácter duradero de la limitación del trabajador, el tribunal nacional deberá basarse en todos los elementos objetivos de los que disponga, en particular, los documentos y certificados relativos al estado de esa persona, redactados de acuerdo con los conocimientos y datos médicos y científicos actuales.

En el caso resuelto por la sentencia del TS de 20 de mayo de 2020, tanto la sentencia del TSJ del País Vasco, contra la que se presentó el recurso para la unificación de doctrina, como la de instancia concluyeron que no cabía apreciar que la situación en la que se encontraba el trabajador despedido fuese constitutiva de discapacidad. El TS apuntó que la resolución recurrida, tomando en consideración la propia sentencia del caso Daouidi, había llegado a la conclusión de que "la situación de IT no puede servir para llevar a considerar al trabajador como afecto de una discapacidad como factor de protección frente a la discriminación". En concreto, el TSJ del País Vasco apuntó que, en el caso que estaba analizando, no constaba ningún dato acerca del carácter duradero de la limitación de la capacidad del demandante, ni siquiera de forma previsible. En consecuencia, no le era posible considerar que se tratase de una situación de discapacidad que podría dar lugar a una discriminación, por lo que concluyó que el despido había sido correctamente calificado como improcedente.

En su sentencia de 22 de mayo de 2020, el TS se dedica, precisamente, a analizar si el fallo de la sentencia del TSJ del País Vasco se ajusta a derecho y, en definitiva, si con su conclusión podría estar contradiciendo la doctrina del TJUE relativa a la interpretación del concepto de discapacidad que figura en la Directiva 2000/78/CE. En este sentido, cabe aclarar que, aunque aporta nuevas aclaraciones sobre la forma en la que hay que interpretar el concepto de discapacidad, en particular en los casos de IT, la sentencia del TJUE sobre el caso Daouidi, elegida como sentencia de contraste en las dos sentencias que se están comentando, sigue la definición del concepto de discapacidad que el TJUE ya había venido utilizando desde su sentencia de 11 de abril de 2013, HK Danmark ${ }^{14}$. En dicha sentencia, el TJUE estableció que "el concepto de "discapacidad", en el sentido de la Directiva 2000/78/CE, debe entenderse

diciembre de 2016, asunto C-395/15", Estudios financieros. Revista de trabajo y seguridad social. CEF, n. 406, 2017.

${ }^{14}$ C-335/11 y 337/11. 
como referido a una limitación, derivada en particular de dolencias físicas, mentales o psíquicas, a largo plazo, que, al interactuar con diversas barreras, puede impedir la participación plena y efectiva de la persona de que se trate en la vida profesional en igualdad de condiciones con los demás trabajadores". En otras palabras, esto supone que la enfermedad -sea curable o incurable- puede equipararse a discapacidad si acarrea limitación, siempre que, además, tal limitación sea de larga duración.

Después de señalar que, para decidir si existe o no discriminación en el caso objeto de análisis, habría que comprobar primero si el trabajador despedido ostenta la condición de discapacitado -sigue, por lo tanto, su doctrina consolidada sobre la cuestión y rechaza la posibilidad de que pueda existir discriminación basada en la enfermedad ${ }^{15}$ - el TS concluyó que los únicos datos de los que dispone son la existencia de dos periodos de IT en los que incurrió el trabajador en los tres meses anteriores al despido, pero que no constan las circunstancias o causas de las bajas. De hecho, como ya se ha apuntado con anterioridad, y al contrario de lo que ocurría, por ejemplo, en el caso Daouidi, no queda claro si derivan del accidente de trabajo, puesto que no ha podido demostrarse cuando se había producido. En consecuencia, el Alto Tribunal concluyó que, en el caso concreto, se hacía extremadamente difícil apreciar que nos encontremos ante una situación de "dolencias físicas, mentales o psíquicas que, al interactuar con diversas barreras, puede impedir la participación plena y efectiva de la persona de que se trate en la vida profesional en igualdad de condiciones con los demás trabajadores", es decir, ante una situación de discapacidad, tal y como la interpretado el TJUE desde la sentencia HK Danmark. A una conclusión similar llega la resolución de 15 de septiembre de 2020. En ella, el TS entendió que, aplicando los criterios de la sentencia sobre el caso Daouidi, no cabe si no desestimar el recurso para la unificación de doctrina, puesto que, en el caso concreto que resuelve, el despido se produce cuando el trabajador había incurrido en un único proceso de IT, del que ni siquiera constan los motivos concretos de las dolencias que han causado su baja médica. Además, tampoco figura ningún otro dato que permita valorar, de forma mínima, la posible discapacidad del trabajador derivada de tales dolencias.

Por otro lado, en la sentencia de 22 de mayo de 2020, el TS también descarta que la ulterior declaración de IP total del actor, posterior a la fecha del despido, tenga alguna relevancia a los efectos de reconocerle las garantías antidiscriminatorias propias de la discapacidad, puesto que estas no están condicionadas a la calificación legal de la capacidad laboral en los términos específicos de la legislación en materia de pensiones de Seguridad Social.

En conclusión, en ambas sentencias, el TS terminó señalando que no cabía sostener que, con carácter genérico, toda decisión ilícita de la empresa, como lo es el despido no justificado, constituya una lesión de derechos fundamentales cuando se dé la circunstancia de que afecta a un trabajador que hubiere estado en situación de IT, sino que, para que exista una discriminación por razón de discapacidad en el sentido de la Directiva 2000/78/CE y el despido

\footnotetext{
${ }^{15}$ STS de 29 de enero 2001 (n. recurso 1566/2000).
} 
pueda ser calificado como nulo por este motivo, es necesario que se cumplan todos los requisitos que el TJUE había venido indicando desde la sentencia HK Danmark, y que ha ampliado en el caso Daouidi. En consecuencia, el TS desestimó los dos recursos para la unificación de doctrina, puesto que entendió que tanto la sentencia del TSJ del País Vasco como la del TSJ de Castilla-León se adaptaban a la doctrina recogida en la sentencia del TJUE sobre el caso Daouidi. El demandante no cumplía con los requisitos para ser considerado persona con discapacidad en ninguno de los dos supuestos, por lo que no tenía derecho al acceso a la tutela antidiscriminatoria por ese motivo. En su sentencia de 15 de septiembre de 2020, el TS puntualizó que, al no existir el menor elemento de juicio que permita considerar que el trabajador despedido pudiera padecer alguna limitación de larga duración que impidiere su participación plena y efectiva en la vida profesional en igualdad de oportunidades con los demás trabajadores, la calificación del despido no puede ser otra que la improcedencia.

\section{VALORACIÓN CRÍTICA}

Los fallos de las sentencias del TS de 20 de mayo y de 15 de septiembre de 2020 ponen de manifiesto, una vez más, las enormes dificultades que entraña la unificación de doctrina sobre la calificación del despido que se ha producido mientras el trabajador se encontraba en situación de IT, o cuando lo había estado previamente. Tal y como ponía establecía la propia sentencia del TJUE en el asunto Daouidi, el análisis del caso concreto juega un papel fundamental en estos supuestos y, en consecuencia, entendió que corresponde al juez nacional decidir acerca de si existen indicios suficientes para entender que la dolencia que da lugar a una IT cumple con los requisitos para ser considerada discapacidad y, por lo tanto, para calificar el despido como nulo.

En sentencias anteriores sobre el particular, ha podido apreciarse que el TS, aun contando con indicios que, a mi juicio, le habrían permitido entender que la situación del trabajador que se encontraba de baja médica era constitutiva de discapacidad, el Alto Tribunal se mostró reticente a reconocer la existencia de una discapacidad en supuestos de enfermedades de larga duración. Sin embargo, en los supuestos resueltos por las sentencias objeto de este comentario, cabe compartir la decisión a la que llega el TS.

En ninguno de los casos que nos ocupan existe información sobre el motivo de las bajas, por lo tanto, el TS no puede llevar a cabo la tarea que el TJUE encomienda al juez nacional, para decidir si pueden equiparse a la discapacidad, porque no tiene datos sobre las perspectivas de evolución de las dolencias que dieron lugar a la situación de IT. El único dato del que dispone es la duración de la baja médica. Ahora bien, en el caso resuelto por la sentencia de 15 de septiembre de 2020, el trabajador llevaba apenas unos días de baja médica en el momento de producirse el despido. Por otro lado, no se sabe si las dos situaciones de IT a las que se refiere la sentencia de 22 de mayo de 2020 obedecen al mismo motivo.

El TS deja claro que el mero hecho de despedir al trabajador mientras se encuentra en situación de IT no implica que dicho despido sea nulo, sino que solo lo será si se entiende que existe discriminación por discapacidad. En este sentido, las demandas que soliciten la declaración de 
nulidad del despido por vulneración del derecho a la no discriminación por razón de discapacidad han de ser muy cautelosas. Deberán aportar suficientes elementos e indicios que permitan a los tribunales valorar si las dolencias que dieron lugar a la situación de IT, efectivamente, cumplen los requisitos exigidos por la doctrina del TJUE para considerar que existe discapacidad. De lo contrario, lo más probable es que los tribunales rechacen la pretensión de nulidad y califiquen el despido como improcedente, aun aplicando la doctrina del TJUE sobre el concepto de discapacidad.

En conclusión, habrá que esperar, para ver si, en los recursos para la unificación de doctrina que resolverá en el futuro, el TS cuenta con los elementos necesarios para valorar si existe o no la discapacidad y, finalmente, se pronuncia a favor de la equiparación de las enfermedades de larga duración que producen limitaciones importantes y duraderas en la capacidad de los trabajadores a la discapacidad, lo que lo llevaría a considerar que los despidos por esta razón son nulos y no improcedentes. 
